\title{
A Pilot Study of Antibody Drug Therapy to Regulate Cell Adhesion in Dental Implants
}

\author{
Mariko Kawai*, Kiyoshi Ohura \\ Department of Pharmacology, Osaka Dental University, Osaka, Japan \\ Email: *kawai-m@cc.osaka-dent.ac.jp
}

How to cite this paper: Kawai, M. and Ohura, K. (2017) A Pilot Study of Antibody Drug Therapy to Regulate Cell Adhesion in Dental Implants. Open Journal of Stomatology, 7, 494-500. https://doi.org/10.4236/ojst.2017.711046

Received: October 19, 2017

Accepted: November 21, 2017

Published: November 24, 2017

Copyright @ 2017 by authors and Scientific Research Publishing Inc. This work is licensed under the Creative Commons Attribution International License (CC BY 4.0).

http://creativecommons.org/licenses/by/4.0/

(c) (i) Open Access

\begin{abstract}
Dental implant therapy is a highly effective treatment for recovering occlusion after tooth loss. An important factor in the success of dental implants is establishing strong osseointegration. If more epithelial cells migrate to the implantbone interface than mesenchymal stem cells, effective osseointegration may fail. Therefore, controlling epithelial cell adhesion and motility would be an effective strategy to increase the success rate of osseointegration. Laminin-332 is a major component of the basement membrane and is composed of three chains $(\alpha 3, \beta 3$ and $\gamma 2)$. It is well-known that laminin-332 regulates cellular functions such as adhesion, proliferation, apoptosis and differentiation. These biological functions depend on changes in the structural arrangement of laminin- 332 by proteolytic cleavage. It is well-known that cleavage of the $\alpha 3$ chain between its LG domains gives laminin-332 its biological function. In this study, we focused on LG domain cleavage and developed antibodies that target the LG domain cleavage site. We attempted to change the biological function of laminin-332 to control cell adhesion for the purpose of regulating dental implant therapy.
\end{abstract}

\section{Keywords}

Laminin-332, Monoclonal Antibody, Cleavage, Cell Adhesion

\section{Introduction}

Dental implant therapy is a key option for the recovery of occlusion following tooth loss [1] [2]. The success of dental implants is related to effective osseointegration [3] [4]. Strong osseointegration may be lost when epithelial cells invade the target sites earlier than mesenchymal stem cells [5] [6]. Therefore, the regulation of epithelial cells and mesenchymal stem cells could facilitate successful osseointegration in dental implant therapy. 
Laminin-332 is an essential component of the basement membrane [7] [8]. Laminin-332 influences cell behavior by interacting with cell surface receptors and regulating cell adhesion, migration, cell-cell communication, proliferation and survival [7] [8]. These biological functions of laminin-332 depend on structural changes caused by cleavages [9] [10]. Laminin-332 is composed of three chains ( $\alpha 3, \beta 3$ and $\gamma 2)$ [11] [12]. Structural changes in $\alpha 3$ or $\gamma 2$ by cleavage are known to play an important role in these biological functions [13] [14].

In the oral cavity, laminin-332 is also an important factor as it influences epithelial cell behavior in dental implant therapy and wound healing [15] [16] [17]. In dental implant therapy, oral epithelial cells play a critical role as they seal the peri-implant tissues when activated by laminin-332 [18]. Moreover, inadequate invasion of epithelial cells to the implant-bone interface induces failure of osseointegration [19].

In this study, we focused on the structural change in the $\alpha 3$ chain of laminin332 by cleavage of LG domains. We attempted to suppress the biological function using monoclonal antibodies targeting the cleavage sites to influence epithelial cell adhesion. If the antibodies are able to control epithelial cell adhesion, we could develop antibody therapy to regulate successful osseointegration in dental implant therapy.

\section{Materials and Methods}

\subsection{Antigen Production for Human Laminin-332}

We focused on structural change in the $\alpha 3$ chain by cleavage of the LG3 and LG4 domains of laminin-332. When compared with mouse and chicken homolog (Figure 1), we synthesized a peptide containing cysteine for cleavage of the LG3 and LG4 domains of laminin-332 by targeting QLLQDTPVAS in the amino acid sequence connecting the LG3 and LG4 domains. To increase the immunogenicity, we synthesized the peptide with keyhole limpet hemocyanin (KLH) as the carrier protein.

\subsection{Immunization, Hybridoma Generation and Selection for Monoclonal Antibody Production}

The peptide antigen targeting the $\alpha 3$ chain was immunized to mice and hybridomas were generated. The animal experiments were conducted in the laboratory of Medical \& Biological Laboratories Co., LTD (Nagoya, Japan). The animal experiments were followed the compliances of the animal experiment of Medical \& Biological Laboratories Co., LTD. To select for monoclonal antibody production, we performed enzyme-linked immunosorbent assay (ELISA) for the peptide antigen for the $\alpha 3$ chain and KLH, and measured OD450 absorbance.

\subsection{Cell Adhesion Assay}

Human epithelial cell line Cas 9-22 was obtained from RIKEN Bio Resources, (Cell Engineering Division, Tsukuba, Japan). Each well of 96-well ELISA plates 


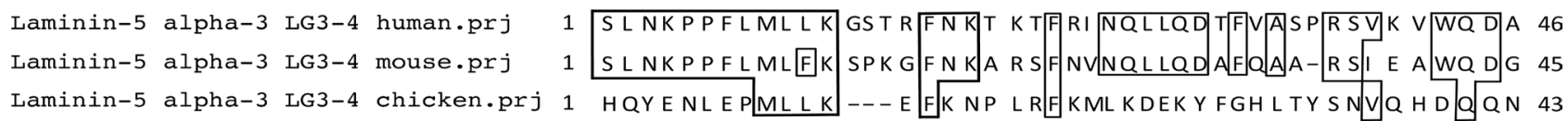

Figure 1. Production of antigen peptide. The antigen peptide targeted the $\alpha 3$ chain of human laminin-332 at the cleavage site between the LG3 and LG4 domains. Homology was assessed with mouse and chicken arraignment.

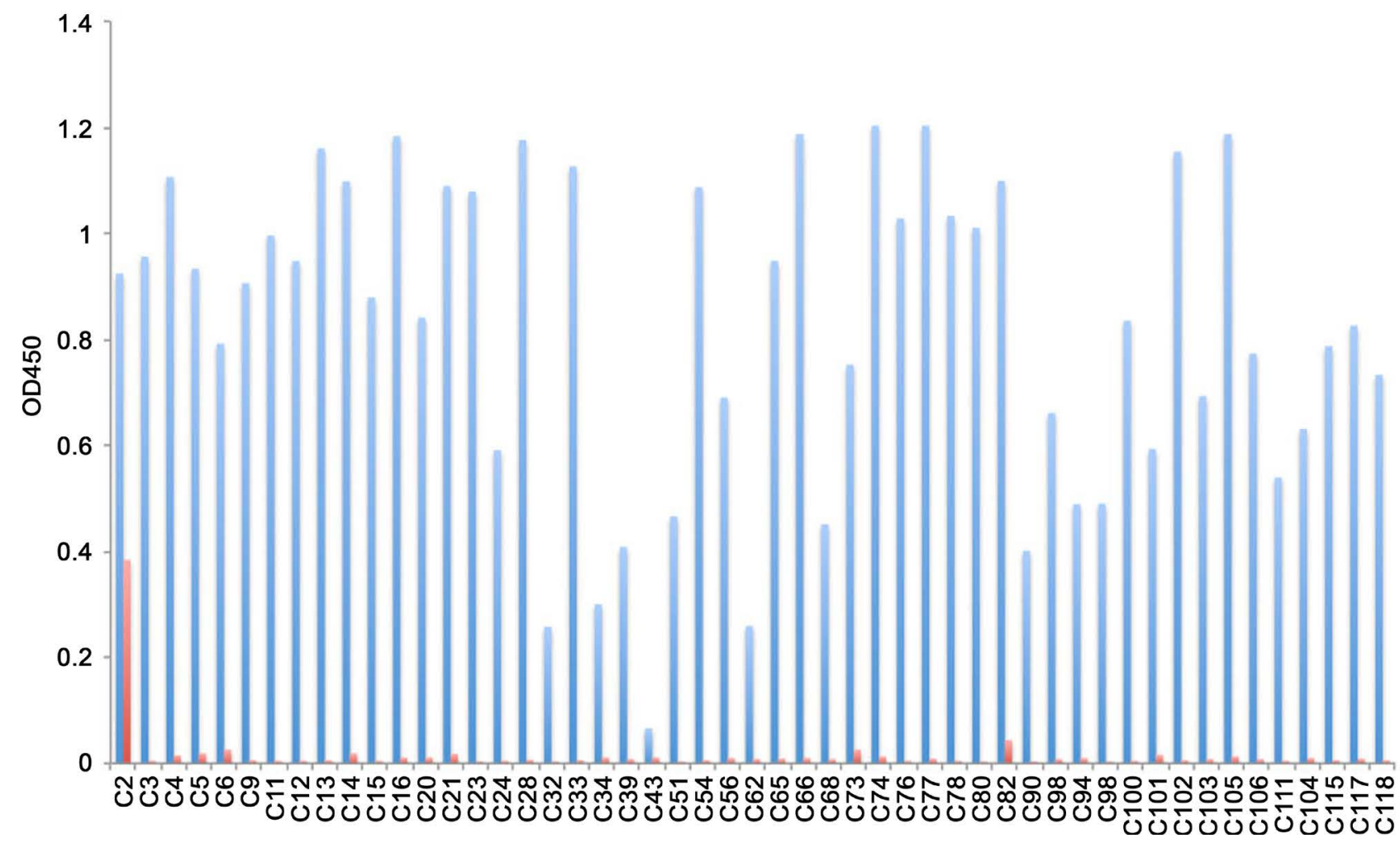

Figure 2. Selection of hybridoma clones. Hybridoma clones were selected based on their affinity to the antigen peptide and the carrier protein, KLH. Red column was represented the affinity to the antigen peptide and blue column was represented to the affinity to the carrier protein, $\mathrm{KLH}$.

(Costar, Cambridge, MA, USA) was coated with recombinant human laminin$332(10 \mu \mathrm{g} / \mathrm{mL})$ with hybridoma clones or culture medium and then blocked with $1.2 \%$ bovine serum albumin. The wells were washed with phosphate-buffered saline (PBS) twice. Cells $\left(2 \times 10^{5}\right)$ were placed into each well and incubated at $37^{\circ} \mathrm{C}$ in the $\mathrm{CO}_{2}$ incubator for $30 \mathrm{~min}$. After the non-adherent cells were removed, the adherent cells were fixed with $4 \%$ paraformaldehyde and washed with PBS twice. The wells were stained with $0.5 \%$ (w/v) crystal violet in $20 \%$ $(\mathrm{v} / \mathrm{v})$ methanol for $10 \mathrm{~min}$. After washing with water, the wells were measured with OD550 $\mathrm{nm}$. The results were analyzed using Student's t-test.

\section{Results}

\subsection{Selection of Hybridoma Clones}

The hybridoma clones were bound with antigen peptides and the OD450 measurements ranged from 0.066 to 1.203 (Figure 2, blue bars). The carrier protein, $\mathrm{KLH}$, was also strongly bound to some clones (Figure 2, red bars). In the criteria 
of the cut off value in the OD450 was less than 1.0 with the affinity of the antigen peptides, and which was over 0.1 of OD450 with the affinity of the carrier protein, KLH was cut off. Therefore, we selected clones that could bind strongly with the antigen peptide but not with $\mathrm{KLH}$, such as C77.

\subsection{Cell Adhesion Activity}

To investigate the influence of the monoclonal antibody on the cell adhesion function of epithelial cells for the $\alpha 3$ chain of laminin-332, we compared it with the cell adhesion function of human epithelial cells from the Cas9-22 cell line. The monoclonal antibody significantly decreased cell adhesion for the laminin$332 \alpha 3$ chain when compared with no monoclonal antibody (Figure 3 ) in both laminin-332 doses, 1 and $10 \mu \mathrm{g} / \mathrm{mL}$.

\section{Discussion}

In the present study, we developed monoclonal antibodies targeting the $\alpha 3$ chain of human laminin-332, which is altered by cleavage between the LG3 and LG4 domains. We succeeded in generating hybridoma clones by immunization of the mice using antigen peptide with the carrier protein, KLH. From the hybridoma clones, we selected the clone with a high affinity for the antigen peptide and a low affinity for the carrier protein, KLH. Finally, we generated a monoclonal antibody targeting the cleavage site of the LG domains in the $\alpha 3$ chain of human laminin-332. Moreover, we investigated whether our monoclonal antibody could regulate the adhesion function of epithelial cells.

We revealed that the monoclonal antibody targeting the $\alpha 3$ chain of human laminin-332 significantly decreased the adhesion function of epithelial cells. Laminin-332 is well-known to play an important role in cell adhesion via structural changes in the $\alpha 3$ or $\gamma 2$ chains [13] [14]. The change in the structure of the $\alpha 3$ chain occurs by cleavage between the LG domains from LG1 to LG5 [20]. It is known that cleavage between LG3 and LG4 is one of the most important events

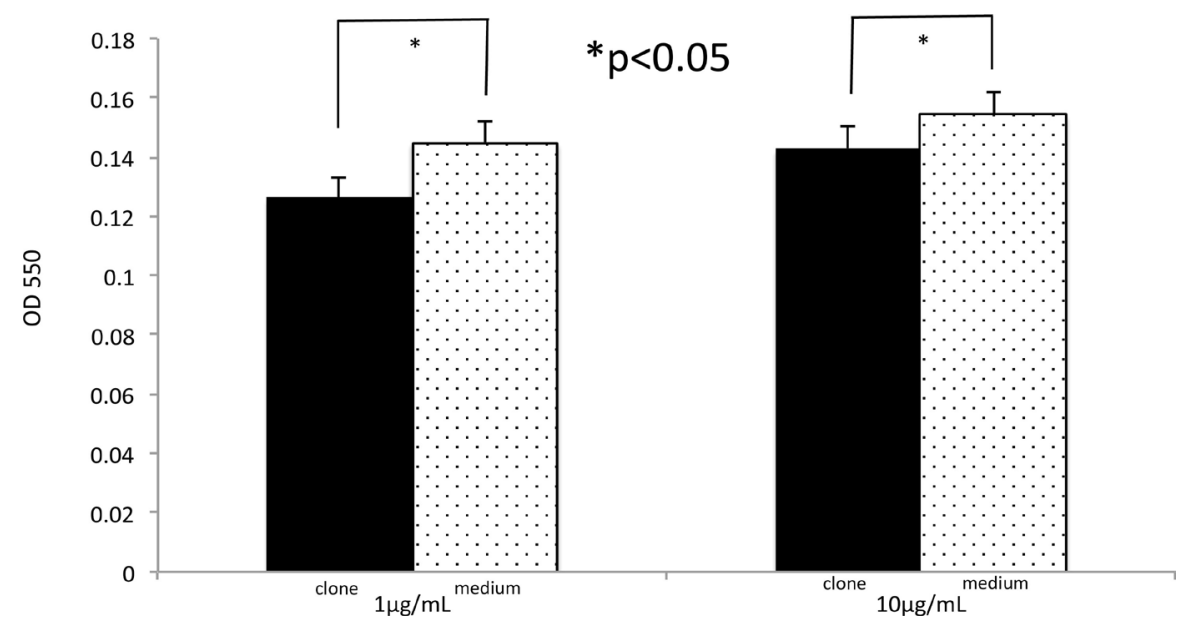

Figure 3. Adhesion assay of human epithelial cells. We revealed that the monoclonal antibody decreased the human epithelial cell adhesion function. 
for activating the biological function of laminin-332 [13] [14].

Strong osseointegration is crucial for successful dental implant therapy [3] [4]. Invasion of primarily epithelial cells, rather than mesenchymal stem cells, to the implant-bone interface may cause failure of osseointegration [19]. Therefore, regulating epithelial cell function would be an effective strategy to obtain successful osseointegration in dental implant therapy.

In a future study, we are planning to investigate whether mesenchymal stem cells or osteoblasts would be influenced by the monoclonal antibody for laminin332. Laminin-332 is also detected in periosteum, not only in the basement membrane [21]. Moreover, laminin-332 affects osteoblast differentiation and calcification [22] [23] [24]. Therefore, laminin-332 plays important roles not only in epithelial cell function but also in the function of mesenchymal cells.

\section{Conclusion}

We concluded that our generated monoclonal antibody, which activates structural changes in laminin-332, has the potential to regulate epithelial cells in dental implant therapy.

\section{Acknowledgments}

This study was supported by Grants-in-Aid for Scientific Research from the Japan Society for the Promotion of Science (Basic Research C Number 22592038).

\section{References}

[1] Misch, C.E. (2007) Contemporary Implant Dentistry. Elsevier, St. Louis.

[2] Pjetursson, B.E., Thoma, D., Jung, R., Zwahlen, M. and Zembic, A. (2012) A Systematic Review of the Survival and Complication Rates of Implant-Supported Fixed Dental Prostheses (FDPs) after a Mean Observation Period of at Least 5 Years. Clinical Oral Implants Research, 23, 22-38. https://doi.org/10.1111/j.1600-0501.2012.02546.x

[3] Sinn, D.P., Bedrossian, E., Vest, A.K. and Bedrossian, V. (2011) Craniofacial Implant Surgery. Oral \& Maxillofacial Surgery Clinics of North America, 23, 321-335. https://doi.org/10.1016/j.coms.2011.01.005

[4] Asbjorn, J. (2009) Osseointegration and Dental Implants. John Wiley \& Sons, New York.

[5] Castagna, L., Polido, W.D., Soares, L.G. and Tinoco, E.M. (2013) Tomographic Evaluation of Iliac Crest Bone Grafting and the Use of Immediate Temporary Implants to the Atrophic Maxilla. International Journal of Oral and Maxillofacial Surgery, 42, 1067-1072. https://doi.org/10.1016/j.ijom.2013.04.020

[6] Brånemark, M. and Worthington, P. (1992) Advanced Osseointegration Surgery: Applications in the Maxillofacial Region. Quintessence Books, Carol Stream.

[7] Domogatskaya, A., Rodin, S. and Tryggvason, K. (2012) Functional Diversity of Laminins. Annual Review of Cell and Developmental Biology, 28, 523-553. https://doi.org/10.1146/annurev-cellbio-101011-155750

[8] Miner, J.H. and Yurchenco, P.D. (2004) Laminin Functions in Tissue Morphogenesis. Annual Review of Cell and Developmental Biology, 20, 255-284. 
https://doi.org/10.1146/annurev.cellbio.20.010403.094555

[9] Goldfinger, L.E., Stack, M.S. and Jones, J.C. (1998) Processing of Laminin-5 and Its Functional Consequence: Role of Plasmin and Tissue-Type Plasminogen Activator. Journal of Cell Biology, 141, 255-265. https://doi.org/10.1083/jcb.141.1.255

[10] Tsubota, Y., Yasuda, C., Kariya, Y., Ogawa, T., Hirosaki, T., Mizushima, H., et al. (2005) Regulation of Biological Activity and Matrix Assembly of Laminin-5 by COOH-Terminal, LG4-5 Domain of $\alpha 3$ Chain. Journal of Biological Chemistry, 280, 14370-14377. https://doi.org/10.1074/jbc.M413051200

[11] Colognato, H. and Yurchenco, P.D. (2000) Form and Function: The Laminin Family of Heterotrimers. Developmental Dynamics, 218, 213-234.

https://doi.org/10.1002/(SICI)1097-0177(200006)218:2<213::AID-DVDY1>3.0.CO; $\underline{2-\mathrm{R}}$

[12] Miyazaki, K. (2006) Laminin-5 (laminin-332): Unique Biological Activity and Role in Tumor Growth and Invasion. Cancer Science, 97, 91-98. https://doi.org/10.1111/j.1349-7006.2006.00150.x

[13] Tsubota, Y., Mizushima, H., Hirosaki, T., Higashi, S., Yasumitsu, H. and Miyazaki, K. (2006) Isolation and Activity of Proteolytic Fragment of Laminin-5 a3 Chain. Biochemical and Biophysical Research Communications, 278, 614-620. https://doi.org/10.1006/bbrc.2000.3851

[14] Rousselle, P. and Beck, K. (2013) Laminin-332 Processing Impacts Cellular Behaveor. Cell Adhesion \& Migration, 7, 122-134. https://doi.org/10.4161/cam.23132

[15] Sawada, T., Yamazaki, T., Shibayama, K., Yamaguchi, Y. and Ohshima, M. (2015) Ultrastructural Immunization of Laminin 332 (laminin 5) at Dentogingical Interface in Macacafuscata Monkey. Medical Molecular Morphology, 48, 104-111. https://doi.org/10.1007/s00795-014-0085-9

[16] Pallala, T., Vitranen, I., Oksanen, J., Jones, J.C. and Hormia, M. (2002) Function of Laminin and Laminin-Binding Integrins in Gingival Epithelial Cell Adhesion. Journal of Periodontology, 73, 709-719. https://doi.org/10.1902/jop.2002.73.7.709

[17] Miyata, K. and Yakebe, J. (2013) Anodized-Hydrothermally Treated Titanium with a Nanotopographic Surface Structure Regulates Integrin $\alpha 6 \beta 4$ and Laminin-5 Gene Expression in Adherent Murine Gingival Epithelial Cells. Archives of Oral Biology, 58, 1696-1708.

[18] Kondo, R., Atsuta, I., Ayukawa, Y., Yamaza, T., Matsuura, Y., Furuhashi, A., et al. (2014) Therapeutic Interaction of Systemically-Administered Mesenchymal Stem Cells with Peri-Implant Mucosa. PLoS ONE, 9, e90681. https://doi.org/10.1371/journal.pone.0090681

[19] Esposito, M., Thomsen, P., Ericson, L.E. and Lekholm, U. (1999) Histopathologic Observations on Early Oral Implant Failures. The International Journal of Oral \& Maxillofacial Implants, 14, 798-810.

[20] Katagiri, F., Hara, T., Yamada, Y., Urushibara, S., Hozumi, K., Kikkawa, Y. and Nomizu, M. (2014) Biological Activities of the Homologous Loop Regions in the Laminin $\alpha$ Chain LG Modules. Biochemistry, 53, 3699-3708. https://doi.org/10.1021/bi5003822

[21] Klees, R.F., Salasznyk, R.M., Kingsley, K., Willians, W.A., Boskey, A. and Plopper, G.E. (2005) Laminin-5 Induces Osteogenic Gene Expression in Human Mesencymal Stem Cells through an ERK-Dependent Pathway. Molecular Biology of the Cell, 16, 881-890. https://doi.org/10.1091/mbc.E04-08-0695

[22] Hashimoto, J., Ogawa, Y., Tsubota, K. and Miyazaki, K. (2005) Laminin-5 Sup- 
presses Chondrogenic Differentiation of Murine Teratocarcinoma Cell Line ATDC5. Experimental Cell Research, 310, 256-269.

[23] Salasznyk, R.M., Klees, R.F., Boskey, A. and Plopper, G.E. (2007) Activation of FAK Is Necessary for the Osteogenic Differentiation of Human Mesenchymal Stem Cells on Laminin-5. Journal of Cellular Biochemistry, 100, 499-514. https://doi.org/10.1002/jcb.21074

[24] Klee, R.F., Salasznyk, R.M., Ward, D.F., Crone, D.E., Williams, W.A., Harris, M.P., Boskey, A., Quaranta, V. and Plopper, G.E. (2008) Dissection of the Osteogenic Effects of Laminin-332 Utilizing Specific LG Domains: LG3 Induces Osteogenic Differentiation, But Not Mineralization. Experimental Cell Research, 314, 763-773. 